\title{
Plasma Renin Activity and Angiotensin Pressor Dose in Hypertension Correlation and Diagnostic Implications
}

\author{
P. WEIDMANN,* M.D. ; P. ENDRES,* M.D.; W. SIEGENTHALER,* M.D.
}

Brit. med. F., 1968, 3, 154-156

\begin{abstract}
Summary: Data obtained from 65 hypertensive $\checkmark$ patients showed a clear-cut positive correlation between peripheral plasma renin activity and the pressor response to exogenous angiotensin II $(r=+0.75)$. For the various causes of hypertension, the mean values of plasma renin concentration were found to correspond closely to the mean values of the angiotensin pressor dose. In individual cases, however, the pressor dose of angiotensin was not found to be a reliable gauge of peripheral venous renin activity.

It was impossible to establish a causal diagnosis from the results of the angiotensin infusion test or the renin level in peripheral blood under normal conditions. If, however, determinations are carried out on the renal venous effluent with sodium restriction and with the patient in the upright position the renin level is very valuable both in the diagnosis of renovascular hypertension and in predicting the probable outcome of surgical treatment.
\end{abstract}

\section{Introduction}

Extensive experimental and clinical studies during recent years have shown the importance of the renin-angiotensinaldosterone system in the regulation of sodium and water balance. There is, however, still some controversy about the significance of these substances in the pathogenesis of hypertension. The fact that markedly raised secretion of renin, angiotensin, and aldosterone may be associated with normal or even reduced blood pressure has been a perpetual source of doubt in this connexion (Gross et al., 1964 ; Brown et al., 1967). The elaboration of methods of assessing these three substances has facilitated the diagnosis of certain forms of hypertension. The combination of high blood pressure, low renin, and elevated aldosterone suggests Conn's syndrome (Conn et al., 1964 ; Brown et al., 1965 ; Weidmann et al., 1967b). Stimulation of the renin-releasing mechanisms seems to be more effective in patients with renovascular hypertension than in those with essential hypertension (Weidmann et al., 1967a) or in normal subjects (Cohen et al., 1966 ; Kaneko et al., 1967).

Kaplan and Silah (1964) introduced the angiotensin infusion test as a simple screening procedure in the evaluation of hypertensives. The usefulness of this test has been confirmed by Hocken et al. (1966). However, Cottier et al. (1966) and Nicotero et al. (1966) found it to be of limited value, and other groups (Breckenridge, 1965 ; Fitz et al., 1965) denied the utility of the technique.

The present study was undertaken for two reasons. (1) Primarily we sought to ascertain whether the angiotensin infusion test could be regarded as a reliable gauge of peripheral venous renin activity. Since the infusion test is technically very much simpler than that for renin, such a study seemed well worth while. (2) In addition, we wished to assess the diagnostic value of both procedures.

- Medizinische Poliklinik of the University of Zurich, Kantonsspital, Zurich, Switzerland.

\section{Material and Methods}

The 65 persons in this inquiry were inpatients and received a normal hospital diet. They all had diastolic pressures of more than $95 \mathrm{~mm}$. $\mathrm{Hg}$ after three hours' bed rest. Diuretics had been withdrawn 7 to 10 days before admission. A few of those with malignant hypertension continued to receive methyldopa. In all patients the phentolamine test and/or vanilloyl-mandelic acid determinations yielded normal results. These 65 hypertensives were divided into several subgroups after further investigation and the results of surgery.

Essential Hypertension without Renal Artery Stenosis.-This group consisted of 22 patients. In all cases blood urea nitrogen and creatinine were within the normal range, and intravenous pyelography and/or renal angiography showed no abnormalities. Specific causative agents were ruled out in every case.

Essential Hypertension with Renal Artery Stenosis.-Eleven patients fell into this group. The criteria for inclusion were the same as for the above group, except that angiography showed unilateral or bilateral renal artery stenosis. Essential hypertension was diagnosed because radioisotopic renogram and/or split function studies failed to show an ischaemic pattern on the affected side.

Renovascular Hypertension.-This group consisted of nine patients. Renal angiography invariably showed evidence of renal artery disease. The diagnosis was based on (1) normalization or marked reduction of blood pressure after operation and (2) an ischaemic pattern in the radioisotopic renogram and the split function studies.

Malignant Hypertension.-Nine patients displayed the clinical features and eyeground characteristics of malignant hypertension. No radiological evidence of renal artery stenosis was found, except in one case in which split function studies and radioisotopic renogram were not indicative of any functionally significant stenosis.

Parenchymal Diseases of Kidney with Hypertension.-The damage to the renal tissue was attributable in five cases to chronic pyelonephritis, in two cases to chronic glomerulonephritis, in one case to periarteritis nodosa, and in one case to hydronephrosis. In a tenth patient the cause could not be identified. In eight of these patients one or both kidneys were shrunken. Arteriography revealed no signs of renal artery stenosis in any of these cases.

Conn's Syndrome.-Four patients had hypertension associated with aldosteronism and hypokalaemic hypernatraemic alkalosis. Adrenal adenomas were found in three of these, while in the fourth case after bilateral operation an extra-adrenal adenoma had to be postulated (Weidmann and Siegenthaler, 1967).

Plasma renin activity was determined in peripheral venous blood samples by a modification of the Boucher method (Boucher et al., 1964). The recovery percentage in our experiments was generally about $75 \%$, and the reproducibility was $\pm 13 \%$ in more than 100 double determinations. Blood samples were drawn with the patient on a normal hospital diet and in the recumbent position for more than six hours (normal range $100-400 \mathrm{~m} \mu \mathrm{g} . / 100 \mathrm{ml} . / 3$ hours incubation).

The angiotensin infusion test was carried out according to the procedure devised by Kaplan and Silah (1964). In 10 
double investigations made within 72 hours the test showed minimum and maximum deviations of 0 and $1.6 \mathrm{~m} \mu \mathrm{g} . / \mathrm{kg} . / \mathrm{min}$., respectively. The quantity of angiotensin per unit time required to raise the diastolic pressure $20 \mathrm{~mm}$. $\mathrm{Hg}$ is defined as the angiotensin pressor dose.

\section{Results}

Essential Hypertension without Renal Artery Stenosis.-Mean peripheral renin activity was $184 \mathrm{~m} \mu \mathrm{g} . / 100 \mathrm{ml}$. (S.D. \pm 81 ). Single values fluctuated between subnormal and upper normal levels (Fig. 1). The mean pressor dose of angiotensin was $4.8 \mathrm{~m} \mu \mathrm{g} . / \mathrm{kg} . / \mathrm{min}$. (S.D. \pm 1.7 ), with extreme values of 3.2 and $10.5 \mathrm{~m} \mu \mathrm{g} . / \mathrm{kg} . / \mathrm{min}$. (Fig. 2).

\section{Discussion}

It is now well established that renin plays an important part in the release of angiotensin. In recent years these two substances have been studied under various physiological and pathological conditions in man. Hypersecretion of renin can be observed in a variety of normotensive, hypotensive, and hypertensive states (Cohen et al., 1964 ; Veyrat et al., 1964 ; Brown et al., 1965, 1967 ; Siegenthaler and Weidmann, 1967). A low renin level is typically found in Conn's syndrome. These variations are almost always accompanied by corresponding changes in serum sodium concentration (Brown et al., 1967).

If it be assumed that the pressor effect of exogenous angiotensin reflects its endogenous plasma concentration (Kaplan and Silah, 1964), then the angiotensin infusion test may be regarded as an indirect method of evaluating angiotensin.

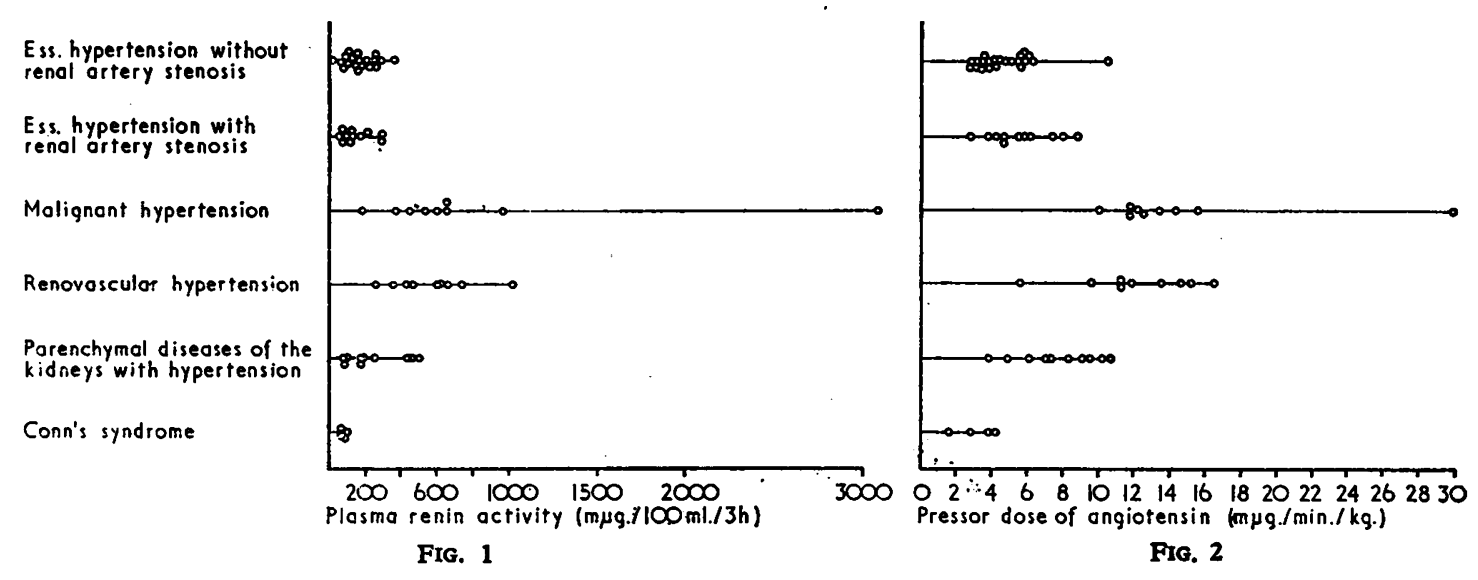

F1:. 1.-Plasma renin activity in 65 patients with hypertension of various causes. Fio. 2.-Results of angiotensin infusion test in 65 patients with hypertension of various causes.

Essential Hypertension with Functionally Insignificant Renal Artery Stenosis.-Mean renin activity and mean angiotensin pressor dose were not significantly different from those found in the first group $(P<0.1$ and $P<0.35$, respectively). Mean renin activity amounted to $151 \mathrm{~m} \mu \mathrm{g} . / 100 \mathrm{ml}$. (S.D. \pm 75 ) (Fig. 1). The mean angiotensin pressor dose was $5.7 \mathrm{~m} \mu \mathrm{g} . / \mathrm{kg} . / \mathrm{min}$ (S.D. \pm 1.9 , with extreme values of 3 and $9 \mathrm{~m} \mu \mathrm{g} . / \mathrm{kg} . / \mathrm{min}$. (Fig. 2).

Renovascular Hypertension.-Mean peripheral renin activity in this group was $614 \mathrm{~m} \mu \mathrm{g} . / 100 \mathrm{ml}$. (S.D. \pm 259 ). This value is significantly higher than in both groups of patients with essential hypertension ( $P<0.0005$ and $P<0.005$, respectively) (Fig. 1). Values obtained from the angiotensin infusion test were also significantly higher than in the patients with essential hypertension (mean $12.2 \mathrm{~m} \mu \mathrm{g} / \mathrm{kg} . / \mathrm{min}$. (S.D. \pm 3.5 ); $\mathrm{P}<0.0005$ ). Single values ranged from 5.3 to $16.5 \mathrm{~m} \mu \mathrm{g} . / \mathrm{kg} . / \mathrm{min}$. (Fig. 2).

Malignant Hypertension.-Mean renin amounted to 849 $\mathrm{m} \mu \mathrm{g} . / 100 \mathrm{ml}$. (S.D. \pm 889 ), angiotensin pressor dose averaged $14.7 \mathrm{~m} \mu \mathrm{g} . / \mathrm{kg} . / \mathrm{min}$. (S.D. \pm 5.9 ). Both values are significantly higher than in patients with essential hypertension $(P<0.01$ and $P<0.005$, respectively). Single renin values varied between 180 and $3,145 \mathrm{~m} \mu \mathrm{g} / 100 \mathrm{ml}$. (Fig. 1). In the angiotensin infusion test all patients required more than $10 \mathrm{~m} \mu \mathrm{g} . / \mathrm{kg} . / \mathrm{min}$. (Fig. 2).

Parenchymal Discase of Kidney with Hypertension.-Plasma renin activity averaged $245 \mathrm{~m} / \mathrm{g} . / 100 \mathrm{ml}$ (S.D. \pm 163 ), with values in the normal range $(100-400 \mathrm{~m} / \mathrm{gg} .100 \mathrm{ml}$.) in seven patients and somewhat raised in three (Fig. 1). Mean pressor dose was $7.8 \mathrm{~m} \mu \mathrm{g} . / \mathrm{kg} . / \mathrm{min}$. (S.D. \pm 2.2 ) (Fig. 2).

Conn's Syndrome.-None of the four patients studied displayed a renin activity of more than $40 \mathrm{~m} \mu \mathrm{g} . / 100 \mathrm{ml}$. (Fig. 1). The average pressor dose was $3.2 \mathrm{~m} \mu \mathrm{g} . / \mathrm{kg} . / \mathrm{min}$. (S.D. \pm 1.3 ) (Fig. 2).
Decreased responsiveness to exogenous angiotensin has been reported in various conditions in which hypersecretion of renin is frequently observed. Attenuated responsiveness has been found in malignant and renovascular hypertension (Kaplan and Silah, 1964 ; Hocken et al., 1966 ; Nicotero et al., 1966), in cardiac insufficiency, nephrotic syndrome, or hepatic cirrhosis (Johnston and Jose, 1963 ; Laragh, 1962 ; Laragh et al., 1964 ; Kaplan and Silah, 1964), during sodium depletion (Ames et al., 1965), in pregnancy (Chesley et al., 1965), in Addison's disease (Küchel et al., 1964), and in Bartter's syndrome (Bartter et al., 1962 ; Beilin et al., 1967). Furthermore, increased sensitivity to exogenous angiotensin has been observed in Conn's syndrome (Kaplan and Sitah, 1964). Therefore a close relation between plasma renin and angiotensin pressor dose is to be expected.

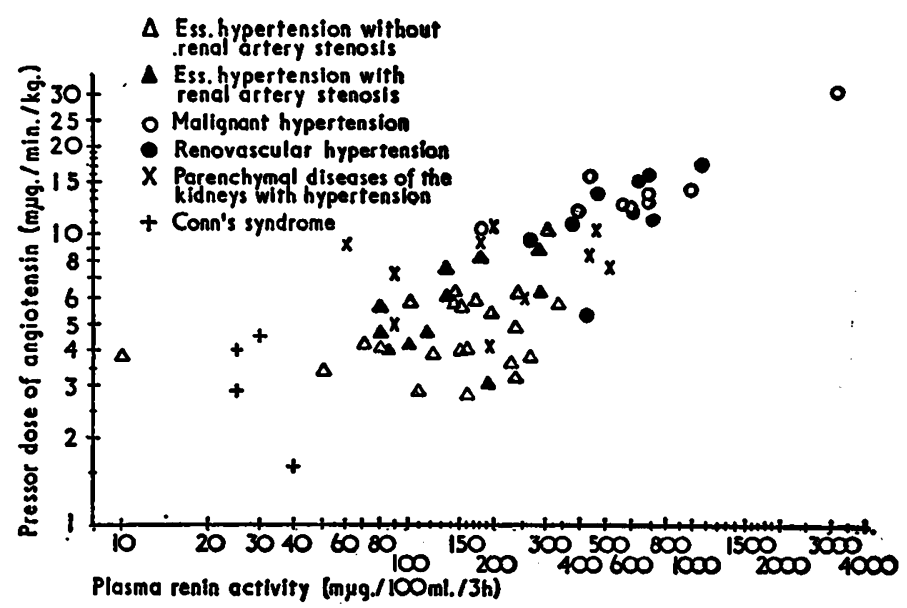

Frg. 3.-Correlation of peripheral plasma renin activity with angiotendo pressor dose in 65 patients with hypertension of various causes. 
The present study shows a positive correlation $(r==+0.75)$ between peripheral venous renin activity and angiotensin pressor dose (Fig. 3). Similar results have recently been reported by Silah et al. (1967). So far as the group means are concerned the angiotensin infusion test corresponds closely to the renin determination. In individual cases, however, it is not a reliable gauge of renin activity. Renin activity indeed is not necessarily representative of true renin concentration (Pickens et al., 1965).

The diagnostic value of both the angiotensin infusion test and the peripheral renin activity, when measured in the recumbent patient receiving a normal sodium intake, is limited by overlapping of values between diagnostic groups (Figs. 1 and 2). Using these two procedures we were unable to separate with certainty essential hypertensives from renovascular hypertensives. However, the diagnostic usefulness of the renin assay is greatly improved if determinations are done during sodium restriction and with the patient in the upright position. As we reported previously, both conditions cause a much higher renin increase in patients with renovascular hypotension than in essential hypertensives (Weidmann et al. 1967a). Similar observations have been published by Cohen et al. (1966), and a recent study by Kaneko et al. (1967) presents further evidence for the existence of an increased sensitivity of the renin-releasing mechanisms in renovascular hypertension. In their patients, as well as ours, excess renin was chiefly secreted by the stenotic kidney. If, therefore, the renin assay is used for detecting renovascular hypertension, determinations should be carried out on renal venous effluent and under the stated stimulatory conditions.

In cases with aldosteronism an increased resistance to the pressor effect of exogenous angiotensin makes Conn's syndrome highly improbable. Like other authors (Kaplan and Silah, 1964), we found a normal or increased angiotensin sensitivity and a low renin activity in such cases (Fig. 2). However, neither the angiotensin infusion test nor the renin assay makes it possible to differentiate with certainty between essential hypertension and Conn's syndrome.

We thank Mrs. Esther Gremli and Miss Helga Hamatschek for their skilled technical assistance. The study was supported by grants of the Swiss National Foundation for Scientific Research and the Foundation for Scientific Research at the University of Zurich.

\section{REFERENCES}

Ames, R. P., Borkowski, A. J., Sicinski, A. M., and Laragh, J. H. (1965). 7. clin. Invest., 44, 1171 .

Bartter, F. C., Pronove, P., Gill, J. R., jun., and MacCardle, R. C. (1962). Amer. .. Med., 33, 811 .

Beilin, L. J., Schiffman, N., Crane, M., and Nelson, D. H. (1967). Brit. med. $7 ., 4,327$.

Boucher, R., Veyrat, R., Champlain, J. de, and Genest, J. (1964). Canad.

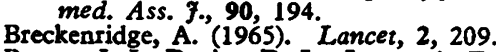

Brown, J. J., Davies, D. L., Lever, A. F., and Robertson, J. I. S. (1965). Brit. med. 7., 2, 1215

Brown, J. J., Lever, A. F., and Robertson, J. I. S. (1967). Schweiz. med. W schr., 97,1635 . Chesley, L. C.' Talledo, E., Bohler, C. S., and Zuspan, F. P. (1965).
Amer. Y. Obstet. Gynec., 91, 837.

Cohen, E. L., Rovner, D. R., and Conn, J. W. (1966). F. Amer. med. Ass., 197, 973.

Cohen, E. L., Rovner, D. R., Conn, J. W., and Blough, W. M. (1964). Clin. Res., 12, 362.

Conn, J. W., Cohen, E. L., and Rovner, D. R. (1964). f. Amer. med. Ass., $190,213$.

Cottier, P., Wettstein, R., Veyrat, R., and Reubi, F. (1966). Helv. med. Acta, 33, Suppl. No. 46, p. 140 .

Fitz, A. E., Valenca, M., and Kirkendall, W. M. (1965). Clin. Res., 13, 206.

Gross, F., Schaechtelin, G., Brunner, H., and Peters, G. (1964). Canad. med. Ass. F., 90, 258.

Hocken, A. G., Kark, R. M., and Passovoy, M. (1966). Lancet, 1, 5.

Johnston, C. I., and Jose, A. D. (1963). f. clin. Invest., 42, 1411 .

Kaneko, Y., Ikeda, T., Takeda, T., and Ueda, H. (1967). ' F. clin. Invest., 46, 705

Kaplan, N. M., and Silah, J. G. (1964). New Engl. Y. Med., 271, 536.

Küchel, O., Horkł', K., Pazourek, M., and Gregorová, i. (1964). Lancet, 2,1316 .

Laragh, J. H.., (1962). Circulation, 25, 1015.

Laragh, J. H., Cannon, P. J., and Ames, R. P. (1964). Canad. med. Ass.

7., 90, 248.
Nicotero, J. A., Moutsos, S. E., Perez-Stable, E., Turrian, H. E., and Shapiro, A. P. (1966). New Engl. F. Med., 274, 1464. Pickens, P. T., Bumpus, F. M., Lloyd, A. M., Smeby, R. R., and Page,

Siegenthaler, W., and Weidmann, P.' (1967). Schweiz. med. W schr., 97, 355.

Silah, J. G., Strong, C. G., Nowaczynski, W., and Genest, J. (1967). Canad. med. Ass. ¥., 96, 1397.

Veyrat, R., Champlain, J. de, Boucher, R., and Genest, J. (1964). Canad. med. Ass. Y., 90, 215.

Weidmann, P., and Siegenthaler, W. (1967). Dtsch. med. Wschr., 92 , 1953.

Weidmann, P., Siegenthaler, W., Möhring, J., Wirz, P., Scheitlin, W., and Rösler, H. (1967a). Schrveiz. med. W schr., 97,1031.

Weidmann, P., Veragut, U., Möhring, J., and Siegenthaler, W. (1967b). Helv. med. Acta, 33, 344.
Mycoplasma pneumoniae, formerly known as Eaton's agent, has in recent years become known as an important cause of

- Consultant Physician, St. George's Hospital, London S.W.1. human respiratory disease. Most serious of the common manifestations of infection is a pneumonia which is sometimes accompanied by the development of cold agglutinins in the patient's serum. More commonly the patient has a mild lower respiratory tract illness, and infection may be subclinical and detectable only by changing titres of antibody against the organism (Chanock et al., 1961). M. pneumoniae is occasionally associated with non-respiratory syndromes. Thus acute haemolytic anaemia with atypical pneumonia may be caused by $M$. pneumoniae infection, and a number of patients with Stevens-Johnson syndrome, or erythema multiforme minor, have shown evidence of infection with this organism. 